\title{
Evaluation of protein change and oxidative stress index after photodynamic therapy of corneal neovascularization
}

\author{
Salwa A. Abdelkawi ${ }^{1}$ and Aziza A. Hassan ${ }^{2}$ \\ ${ }^{1}$ Department of Vision Science, Biophysics and Laser Science Unit, Research Institute of Ophthalmology, Giza, Egypt \\ ${ }^{2}$ Ophthalmic Unit, National Institute for Laser Enhanced Science, Cairo University, Egypt
}

\begin{abstract}
The aim of the present study was to evaluate the change in corneal protein and oxidative stress state after using photodynamic therapy (PDT) for treatment of experimental corneal neovascularization (NV) with benzoporphyrin derivative (BPD). One group was considered as control ( $N=10$ eyes), corneal NV was induced in $25 \mathrm{New}$ Zealand male rabbits $(N=50$ eyes) after placing silk sutures in the corneal limbus. Five rabbits with corneal NV were left without any treatment, and 20 rabbits were administered by intravenous injection with Verteporfin at a dose of $1.5 \mathrm{mg} / \mathrm{kg}$. Diode laser $(660 \mathrm{~nm})$ was applied for 5 minutes with a power of $50 \mathrm{~mW} / \mathrm{cm}^{2}$. For a period of 4 weeks, five rabbits were selected and sacrificed weekly ( $N=10$ eyes each). The corneas were isolated for determination of protein content, SDS-PAGE, total antioxidant capacity (TAC), total oxidative capacity (TOC), malondialdhyde (MDA) and oxidative stress index (OSI). The results indicated that corneal NV induced changes in the content and composition on the corneal protein and gradual improvement of the cornea after the $3^{\text {rd }}$ and $4^{\text {th }}$ week of PDT was detected. Furthermore, the oxidative/antioxidative balance shifted towards the antioxidative status that helped to prevent further damage.
\end{abstract}

Key words: Corneal protein — Electrophoresis - Oxidative stress - Photodynamic therapy - Verteporfin

Abbreviations: MDA, malondialdehyde; NV, neovascularization; OSI, oxidative stress index; PDT, photodynamic therapy; TAC, total antioxidant capacity; TOC, total oxidative capacity.

\section{Introduction}

The cornea is the transparent front part of the eye that covers the iris, pupil, and anterior chamber. Because transparency is of prime importance, the cornea does not have blood vessels; it receives nutrients via diffusion from the tear fluid, the aqueous humor. The cornea has no blood supply; it gets oxygen directly from the air through the tears (Cassin and Solomon 1990).

Corneal neovascularization (NV) is the main cause of blindness worldwide, and it caused by many factors such as, inflammation, degenerative disorder, infection, chemi-

Correspondence to: Salwa A. Abdelkawi, Department of Vision Science, Biophysics and Laser Science Unit, Research Institute of Ophthalmology, P. O. Box 12511, 2 El-Ahram St., Giza, Egypt E-mail: saelkawi@yahoo.com cal burns, and long-term contact lens wear (Lee et al. 1998). The lack of blood vessels in the cornea allows the passage of light and the absorption of oxygen from the air. Corneal NV causes corneal hypoxia, and the body attempts to provide the eye with the necessary nutrients and oxygen to the corneal tissue by increasing the activity of vascular endothelial growth factor (VEGF), inducing the formation of new vascular growth (The Association for Research in Vision and Ophthalmology, ARVO 2008). The primary treatments of these vessels are the topical corticosteroids and non-steroids anti-inflammatory drugs. However, if the vessels have been established for an extended period, these treatments are ineffective (Epstein et al. 1987). Although, argon laser NV has been reported, this method achieved an inadequate effect because of the high incidence of recanalization and thermal damage to the adjacent tissues (Nirankari and Bear 1986; Marsh 1988). 
Recent advances in understanding the molecular mechanisms have facilitated the development of new therapies for neovascular ocular diseases (Lynch and Cheng 2007; Hosseini and Nejabat 2007; Kim et al. 2008). Corneal NV is a challenging condition, and because corneal clarity and avascularity are critical for maintaining vision, developing treatments for corneal NV is crucial. In photodynamic therapy, systemically administered porphyrin derivatives accumulate in proliferating endothelial cells. Laser energy is then used to activate the porphyrin derivatives librating cytotoxic oxygen free radicals (Gohto et al. 2000a,b). This reactive oxygen species (ROS) facilitate the damage to vascular endothelium by activates platelets, leading to the formation of thrombus that occlude the target vessels.

Verteporfin $\left(\mathrm{C}_{41} \mathrm{H}_{42} \mathrm{~N}_{4} \mathrm{O}_{8}\right)$ otherwise known as benzoporphyrin derivative (trade name Visudyne ${ }^{\circledast}$ ), is a medication used as antineoplastic agents, photosensitizing agents and antineovascularisation agents. Verteporfin was used in conjunction with a laser to eliminate the abnormal blood vessels in the eye associated with conditions such as the wet form of macular degeneration. Verteporfin accumulates in these abnormal blood vessels and, when stimulated by non-thermal red light laser in the presence of oxygen, produces highly reactive short-lived singlet oxygen and other reactive oxygen radicals, resulting in local damage to the endothelium and blockage of the vessels (Nowak-Sliwinska et al. 2006; Chan et al. 2010).

The aim of the present work was to study the change in corneal protein content and composition and assess the mechanism of oxidant-antioxidant imbalance produced secondary to treatment of corneal NV with PDT.

\section{Materials and Methods}

\section{Animals}

New Zealand male rabbits $(n=30)$ weighing $2-2.5 \mathrm{~kg}$ were selected from the animal house of Research Institute of Ophthalmology, Giza, Egypt. The animals were maintained in a standard 12-h light/dark cycle with free access to water and balanced diet. All procedures were conducted according to the principles enunciated in the Guide for Care and Use of Laboratory Animals (NIH publication No. 85-23). They were subjected to experimental protocols approved by the local experimental ethics committee of ophthalmic and vision research.

\section{Clinical examination}

All rabbits' eyes were examined by slit lamp biomicroscope before induction of corneal neovascularization. The results indicate no signs of edema or intraocular inflammation in all eyes.

\section{Corneal neovascularization}

Five rabbits were used as control, and 25 rabbits $(N=50 ; N$, number of eyes) were generally anesthetized using intramuscular Xylaject $(0.2 \mathrm{ml} / \mathrm{kg})$ and ketamine hydrochloride $(0.6 \mathrm{ml} / \mathrm{kg})$. Benoxinate eye drops $(0.4 \%)$ was used for local anesthesia. Corneal neovascularization was induced by a three 7.0 silk sutures at midstromal depth approximately $1 \mathrm{~mm}$ from the limbus (Schmidt-Erfurth et al. 1995). Antiinflammatory eye drops (Diclofenac) was used three times daily to treat pain and inflammation. After four days slit lamp examination was performed to determine the area of corneal NV.

\section{Photodynamic therapy}

Five rabbits with corneal NV $(N=10)$ were left without any treatment and the rest of rabbits $(N=40)$ were generally anesthetized, and verteporfin (Visudyne ${ }^{\circledR}$; Novartis AG, Basel, Switzerland) with a dose of $1.5 \mathrm{mg} / \mathrm{kg}$ was administered by slow intravenous injection in the marginal ear vein. After 15 minutes, rabbit's eyes were exposed to direct contact of diode laser (SIM-MED Gallium Midi, UK) at $660 \mathrm{~nm}$ for five minutes and a power of $50 \mathrm{~mW} / \mathrm{cm}^{2}$. For a period of four weeks, five selected animals were sacrificed weekly, and the eyes were enucleated; the neovascularized portions of the corneas were isolated for determination of total protein content, SDS-PAGE, total antioxidant capacity (TAC), total oxidative capacity (TOC) and malondialdhyde (MDA).

A tissue samples from a neovascularized portion of the corneas were accurately weighed and homogenized using cell homogenizer (type Tübingen 7400, Germany), in a 10fold volume of $20 \mathrm{mM}$ ice-cold tris- $\mathrm{HCl}$ buffer, $\mathrm{pH}$ 7.4. The homogenate was centrifuged for 20 minutes at 10,000 rpm in a bench centrifuge (Awel centrifuge MS 20, France). The resultant supernatant was used for determination of total protein content and TAC, TOC, oxidative stress index (OSI) and MDA. All reagents were of the highest purity available. Chemicals for measurement of TAC and TOC were purchased from Sigma Chemical Co. (St. Louis, MO).

\section{Protein analysis}

Corneal protein content was determined according to the method of Lowry et al. (1951). The developing color was measured with a spectrophotometer (type UV-visible recording 240 Graphical, Shimatzu, Japan) at $750 \mathrm{~nm}$. Protein composition of the cornea was analyzed by SDS-PAGE according to its molecular weight by the method of Laemmli (1970) using 3\% stacking gel and 10\% separating gel. The gel was scanned using scanner model SG-700 Imaging Densitometer (Bio Rad). 
The total antioxidative capacity (TAC)

The supernatants were subjected to biochemical analysis of the total antioxidative capacity using a colorimetric method performed by the reaction of antioxidants in the sample with a defined amount of exogenously provided hydrogen peroxide $\left(\mathrm{H}_{2} \mathrm{O}_{2}\right)$. The TAC was determined at $505 \mathrm{~nm}$ by an enzymatic reaction and the results are expressed in terms of $\mathrm{mM} / \mathrm{g}$ tissue (Koracevic 2001).

\section{Measurement of total oxidant capacity (TOC)}

The TOC levels of the cornea were determined using a colorimetric method (Aebi 1984). Therefore, the color intensity, measured spectrophotometrically at $510 \mathrm{~nm}$, is related to the total number of oxidant molecules present in the sample. The results are expressed in terms of $\mathrm{mM} / \mathrm{g}$ tissue.

\section{Measurement of malondialdehyde (MDA)}

Quantitative determination of MDA was carried out colorimetrically using kit purchased from Biodiagnostic Co., Egypt, according to method described by Ohkawa et al. (1979); Martinez et al. (2002). The determination of lipid peroxidation product (MDA) was measured by thiobarbituric acid assay, which is based on MDA reaction with thiobarbituric acid to produce thiobarbituric acid reactive substances (TBARS), a red species that absorbs at $535 \mathrm{~nm}$.

\section{Determination of oxidative stress index (OSI)}

The ratio of TOC to TAC was accepted as OSI. The OSI values were calculated according to the following formula: OSI $=$ TOC $(\mathrm{mM} / \mathrm{g}$ tissue $) / \mathrm{TAC}$ (mM/g tissue) (Demirbag et al. 2007).

\section{Statistical analysis}

Statistical analysis was performed using Student's $t$-test. The results were expressed as the mean \pm standard deviation (SD). Statistical significance was assumed at a level of $p<0.05$ (Snedecore and Cochran 1976).

\section{Results}

\section{Protein analysis}

The total protein concentration of the control cornea was $28.3 \pm 0.4 \mathrm{mg} / \mathrm{g}$ tissue (Fig. 1). This value was significantly increased in corneal NV group to $71.4 \pm 0.3(p<0.001)$ with percentage change of $152 \%$ with respect to the control. After 1 and 2 weeks of PDT, the protein content decreased to 67.3 \pm 0.3 and $54.1 \pm 0.6 \mathrm{mg} / \mathrm{g}$ tissue, respectively $(p<0.001)$. After 3 and 4 weeks of PDT, the protein content showed progressive reduction nearly to the control value $(47.9 \pm 0.7$ and $26.4 \pm 0.4 \mathrm{mg} / \mathrm{g}$ tissue, respectively).

The SDS-PAGE profiles of control and neovascularized corneal protein were illustrated in Fig. 2. The control was characterized by the presence of 12 peaks that varies in their molecular weights, broadening and intensities. After induction of corneal NV, the pattern showed changes in the intensities of the bands accompanied with the appearance of new fractions at 185, 160,130, 100 and $12 \mathrm{kD}$. One week after PDT, there was a pronounced shift towards high molecular weight region with the appearance of two new protein fractions at 204 and $157 \mathrm{kD}$ accompanied with broadening and increase in the intensity of the fraction at $89 \mathrm{kD}$. Moreover, after two weeks the pattern of electrophoresis showed the appearance of new fraction at $186 \mathrm{kD}$ and decreasing in the intensity of the band at $89 \mathrm{kD}$. After the $3^{\text {rd }}$ week of PDT, there was distinct recovery in the electrophoresis patterns. Furthermore, after the $4^{\text {th }}$ week of PDT the corneal protein pattern revealed obvious improvement that approximately resembling the control. In contrast, the recovery effect of PDT after 4 weeks was higher relative to the corresponding pattern with corneal NV.

\section{Oxidative stress markers}

Mean and SD values of TAC, TOC and MDA levels for control and all treated groups were presented in Table 1. There were significant differences than the control in TAC and TOC levels in all groups. The data showed a significant reduction in TAC $(-18.8 \%, p<0.05)$ from $156 \pm 2.1 \times 10^{-4} \mathrm{mM} / \mathrm{g}$ tissue for the control to $129 \pm 1.5 \times 10^{-4} \mathrm{mM} / \mathrm{g}$ tissue after corneal $\mathrm{NV}$, and very high significant increase in TOC $(61.6 \%, p<$ 0.001 ) from $8.23 \pm 0.6 \mathrm{mM} / \mathrm{g}$ tissue for the control to13.3

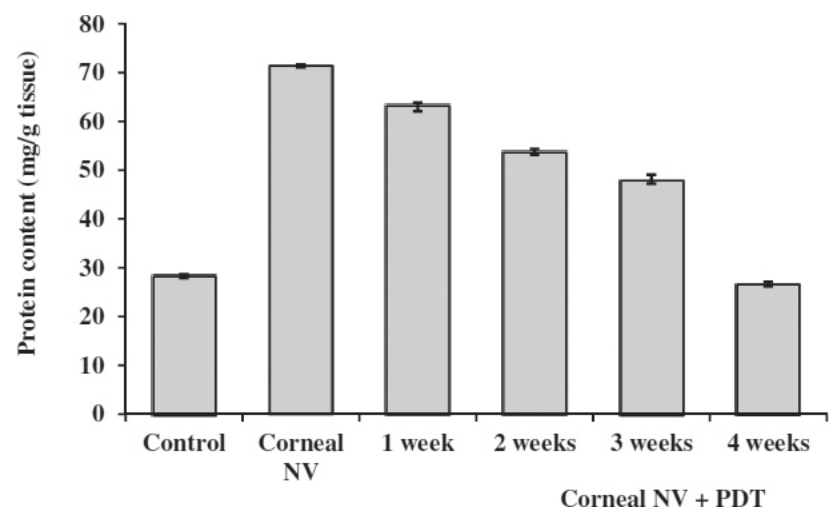

Figure 1. Protein content of rabbit cornea for control group, corneal NV group and groups exposed to PDT. NV, neovascularization; PDT, photodynamic therapy. 

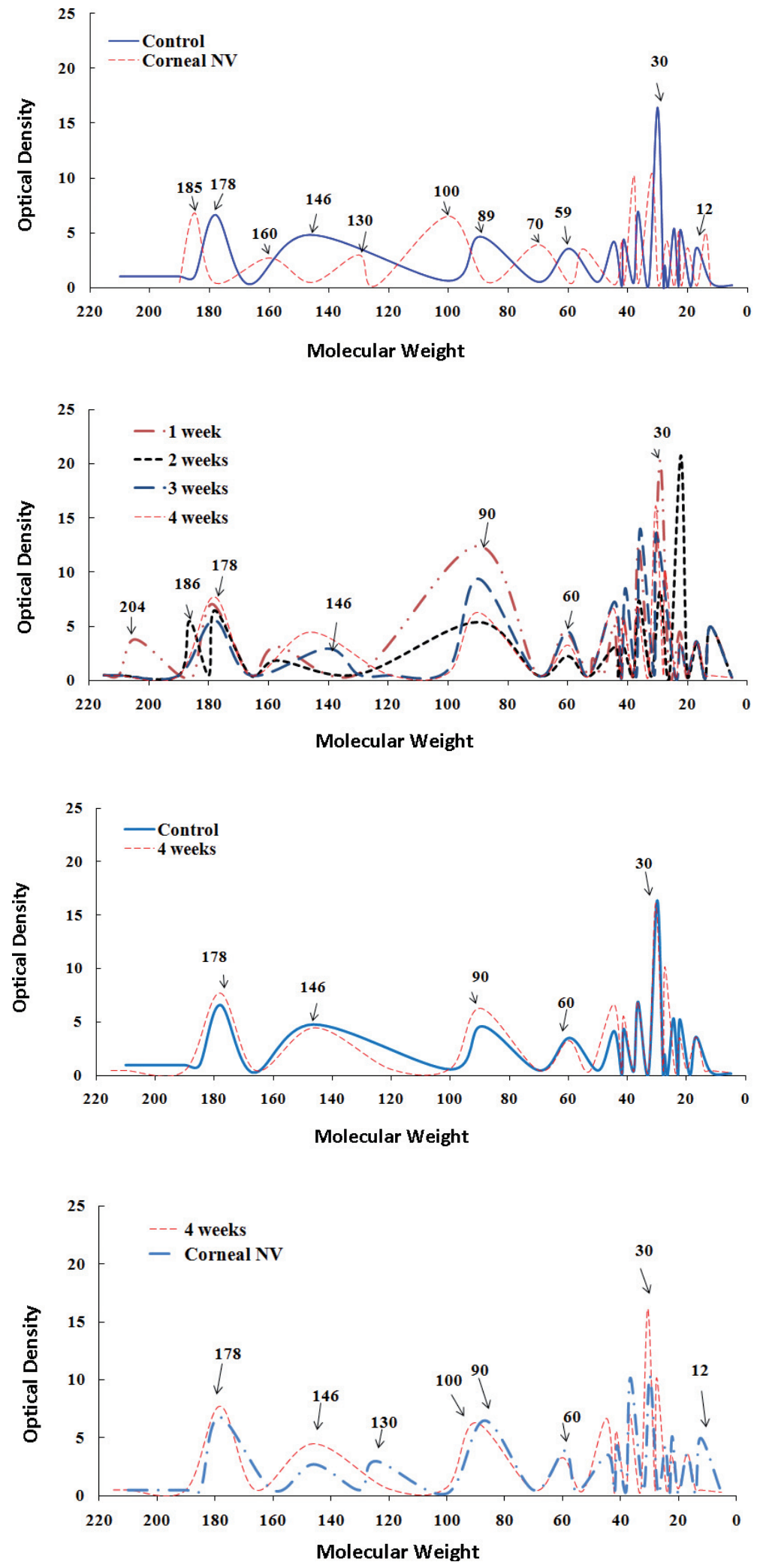

Figure 2. SDS-PAGE pattern of rabbits' corneal protein for control $v s$. corneal NV group; 1, 2, 3 and 4 weeks after PDT exposition; control $v s .4$ weeks after PDT exposition; and 4 weeks after PDT vs. corneal NV group. $\pm 0.7 \mathrm{mM} / \mathrm{g}$ tissue after corneal NV. After 1,2 , 3 and 4 weeks of PDT, there were progressive increases in TAC for all studied groups with values of $208 \pm 2.5,266 \pm 1.9,288 \pm 2.6$ and 142 $\pm 1.2\left(\times 10^{-4} \mathrm{mM} / \mathrm{g}\right.$ tissue $)$, respectively, with a significant inverse relation between the TAC and TOC levels of the third and fourth week. In groups of PDT after 3 and 4 weeks, Table 1 shows that the levels of MDA are significantly correlated with TOC. In contrast, there was an inverse relationship between MDA and TAC levels after 4 weeks of PDT.

OSI illustrated the ratio of TOC to TAC and determined the oxidative/ antioxidative balance (Fig. 3). In case of corneal NV group, the data indicated shifting towards oxidative status $(1028 \pm 22)$, and oxidative stress was very high compared with the control group (525 \pm 18$)$. After 1, 2, 3, and 4 weeks of PDT the oxidative stress was shifted towards antioxidative status with a values of $845 \pm 11,781 \pm 2,655 \pm 5$ and $454 \pm 4$, respectively.

\section{Discussion}

Photodynamic therapy has gained increasing interest in ophthalmology, representing an experimental tool for the diagnosis and treatment of tumors located in the eye. PDT is a treatment modality involving the administration of photosensitizing compound, which selectively accumulates in the hyperproliferative target cells followed by local irradiation of lesion with visible light. The combination of two nontoxic elements, i. e. drug and light, in the presence of oxygen results in the selective destruction of the target tissue by necrosis and apoptosis (Lukšienė 2003).

Numerous investigations supported the idea that the efficacy of PDT is directly related to the yield of $\mathrm{O}_{2}$ in the tumor environment and the yield of $\mathrm{O}_{2}$ depends on the concentration of oxygen in the tissue. Hypoxic cells are very resistant to photosensitization and the photodynamic reaction mechanism itself may consume oxygen at a rate sufficient to inhibit further photosensitization effects. It has been suggested, that hyperbaric oxygen might enhance the photosensitization effect (Henderson and Dougherty 1992).

Verteporfin, a liposomal formulation of benzoporphyrin derivative monoacid ring A (BPD- 
Table 1. Malondialdehyde (MDA), total oxidative capacity (TOC), total antioxidative capacity (TAC) of rabbits' cornea for control, corneal NV, and groups exposed to PDT

\begin{tabular}{lcccc}
\hline Group & & $\begin{array}{c}\text { MDA } \\
(\mathrm{nM} / \mathrm{g} \text { tissue })\end{array}$ & $\begin{array}{c}\text { TOC } \\
(\mathrm{mM} / \mathrm{g} \text { tissue })\end{array}$ & $\begin{array}{c}\text { TAC } \\
\left(10^{-4} \mathrm{mM} / \mathrm{g} \text { tissue }\right)\end{array}$ \\
\hline Control & $172.3 \pm 6.4$ & $8.23 \pm 0.6$ & $156 \pm 2.1$ \\
\hline Corneal NV & & $278.4 \pm 4.3$ & $13.3 \pm 0.7$ & $129 \pm 1.5$ \\
& 1 Week & $289.5 \pm 3.5$ & $17.6 \pm 0.5$ & $208 \pm 2.5$ \\
Corneal NV & 2 Weeks & $396.6 \pm 5.7$ & $20.8 \pm 0.6$ & $266 \pm 1.9$ \\
+ PDT & 3 Weeks & $356.5 \pm 6.1$ & $18.8 \pm 0.8$ & $288 \pm 2.6$ \\
& 4 Weeks & $152.2 \pm 4.5$ & $6.48 \pm 0.3$ & $142 \pm 1.2$ \\
\hline
\end{tabular}

$\mathrm{NV}$, neovascularization; PDT, photodynamic therapy.

MA), is being used clinically in photodynamic therapy for age-related macular degeneration (Ichikawa 2004). Verteporfin is transported in the plasma primarily by lipoproteins (especially low-density lipoproteins), are known to deliver hydrophobic materials to tumor cells (de Smidt et al. 1993; Koller-Lucae et al. 1999; Pan et al. 2004).

In the present study, the change in corneal protein after induction of NV was evaluated. The results indicated elevated levels of corneal protein percentage above the baseline of the control (152\%). Furthermore, decreasing in protein contents were observed during the next four weeks after exposure to PDT due to regression of corneal NV. These results suggested that, the induction of corneal NV caused corneal hypoxia, inducing the formation of new vascular growth by increasing the activity of VEGF (The Association for Research in Vision and Ophthalmology ARVO, 2008). This process was associated with an enhanced formation of blood vessels containing blood component, leading to elevated levels of protein content of the cornea and therefore changing in its SDS-electrophoresis pattern. Furthermore, once Verteporfin was activated by light in the presence of oxygen, highly reactive, short-lived singlet oxygen and reactive oxygen radicals are generated. Light activation of Verteporfin resulted in local damage to neovascular endothelium, vessel occlusion, leading to gradual improvement in protein content and in electrophoresis patterns during the next four weeks after PDT indicating the suppression of vessels growth and the survival of corneal tissue.

The present study is the first to evaluate levels of TAC, TOC and OSI of neovascularized cornea and cornea exposed to PDT. It is well known that various antioxidants have an additive effect, protecting the organism from free radicals (Wayner et al. 1987). In this respect, evaluation of TAC provides information about the antioxidative capacity of the tissues (Erel 2004).

Based on current knowledge, ROS are produced in metabolic and physiological processes, and harmful oxidative reactions may occur in organisms that remove them via enzymatic and non-enzymatic antioxidative mechanisms.
Unstable free radical species attack cellular components causing damage to lipids, proteins, and DNA, which can initiate a chain of events resulting in the onset of a variety of diseases. Meanwhile, living organisms have developed complex antioxidant systems to counteract ROS and to reduce their damage (Yanik et al. 2004; Harma et al. 2005; Yeni et al. 2005).

These antioxidant systems include enzymes such as superoxide dismutase, catalase, and glutathione peroxidase; macromolecules such as albumin, ceruloplasmin, and ferritin; and an array of small molecules, including ascorbic acid, $\alpha$-tocopherol, $\beta$-carotene, reduced glutathione, uric acid, and bilirubin. The sum of endogenous and food-derived antioxidants represents the total antioxidant activity of the system. The cooperation among different antioxidants provides greater protection against attack by reactive oxygen or nitrogen species, than any single compound alone. Thus, the overall antioxidant capacity may provide more relevant biological information compared to that obtained by the measurement of individual components, as it considers the cumulative effect of all antioxidants present in tissues (Koracevic et al. 2001).

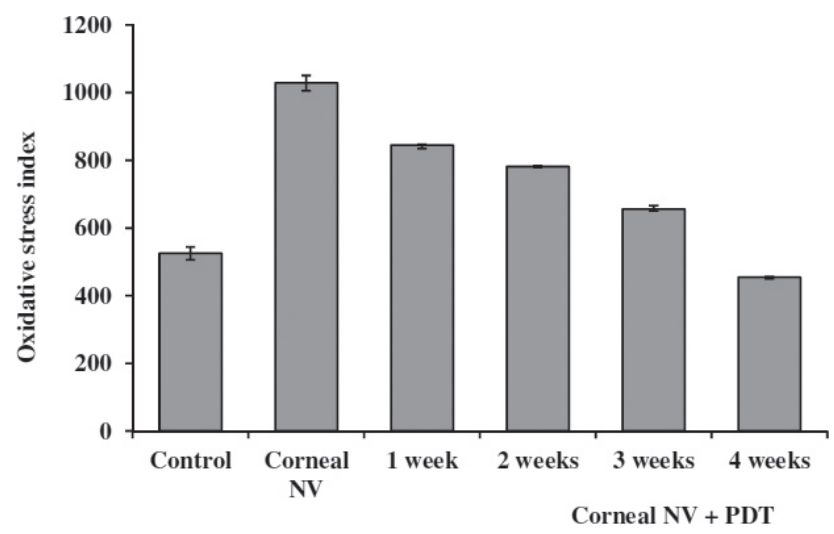

Figure 3. Oxidative stress index (OSI) of rabbit cornea for control group, corneal NV group, and different groups exposed to PDT. 
Oxidative stress resulted from increased number of lipid and protein oxidation products and decreased number of antioxidant enzymes and vitamins (Koksal and Kurban 2010). In addition, OSI, the ratio of the corneal TOC level to TAC, is an indicator of oxidative stress reflecting the redox balance between oxidation and antioxidation (Erel 2005; Demirbag 2007; Rabus et al. 2008).

In the present study, we observed decrease in the TAC and increase in TOC of the cornea after induction of corneal NV causing change in OSI by $103 \%$. Furthermore, PDT stimulates the antioxidant defense system by elevation of TAC because it induces more oxidative stress. These data indicated that PDT using liposomal Verteporfin, showed a stronger cytotoxicity to neovascular endothelium that observed after 1 week of laser treatment. Furthermore, since this toxic effect of PDT appeared time dependently, the results indicated gradual improvement of the cornea after the $3^{\text {rd }}$ and $4^{\text {th }}$ week of PDT. Lipid peroxidation (MDA) has been used to reflect oxidative stress. The present results revealed that, the levels of the oxidative stress biomarker MDA were significantly increased in corneal NV group and in all treated groups except after three and four weeks compared to the control (Table 1). This was considered the cause of an imbalance between oxidative and antioxidative status. Interestingly, these results suggested that the oxidative/antioxidative balance shifts towards the antioxidative status and PDT with Verteporfin caused growth cycle arrest that helps to prevent further damage and give the cell time to repair the defect. These results agree with previous reports of Nowak-Sliwinska et al. (2006) and Chan et al. (2010). They concluded that, damaged endothelium is known to release procoagulant and vasoactive factors through the lipo-oxygenase (leukotriene) and cyclo-oxygenase (eicosanoids such as thromboxane) pathways, resulting in platelet aggregation, fibrin clot formation and vasoconstriction. In addition, the antiproliferative activities would be not due to direct toxicity against neovasularized cells but due to blocking of some proliferative steps (Bortner et al. 2002).

\section{Conclusion}

This paper contribute not only to a better understanding of mechanism of oxidant-antioxidant imbalance produced secondary to treatment of corneal neovascularization with PDT but also to the prediction of TAC, TOC and OSI levels as useful markers for evaluating changes in the oxidative status caused by PDT.

\section{References}

Aebi H. (1984): Catalase in vitro. Methods Enzymol. 105, $121-126$ http://dx.doi.org/10.1016/S0076-6879(84)05016-3
Bortner C. D., Cidlowski J. A. (2002): Cellular mechanisms for the repression of apoptosis. Ann. Rev. Pharmacol. Toxicol. 42, 259-281

http://dx.doi.org/10.1146/annurev.pharmtox.42.083101.143836

Cassin B., Solomon S. (1990): Dictionary of Eye Terminology. Triad Publishing Company, Gainsville, Florida

Chan W. M., Lim T. H., Pece A., Silva R., Yoshimura N. (2010): Verteporfin PDT for non-standard indications - a review of current literature. Graefes Arch. Clin. Exp. Ophthalmol. 248, 613-626 http://dx.doi.org/10.1007/s00417-010-1307-z

Demirbag R., Gur M., Yilmaz R., Kunt A. S., Erel O., Andac M. H. (2007): Influence of oxidative stress on the development of collateral circulation in total coronary occlusions. Int. J. Cardiol. 116, 14-19 http://dx.doi.org/10.1016/j.ijcard.2006.02.012

de Smidt P. C., Verslus A. J., van Berkel T. J. (1993): Properties of incorporation, redistribution, and integrity of porphyrin-lowdensity lipoprotein complexes. Biochemistry 32, 2916-2922 http://dx.doi.org/10.1021/bi00062a023

Epstein R. J., Stulting R. D., Hendricks R. L., Harris D. M. (1987): Corneal neovascularization: Pathogenesis and inhibition. Cornea 6, 250-257 http://dx.doi.org/10.1097/00003226-198706040-00004

Erel O. (2004): A novel automated method to measure total antioxidant response against potent free radical reactions. Clin. Biochem. 37, 112-119 http://dx.doi.org/10.1016/j.clinbiochem.2003.10.014

Erel O. (2005): A new automated colorimetric method for measuring total oxidant status. Clin. Biochem. 38, 1103-1111

http://dx.doi.org/10.1016/j.clinbiochem.2005.08.008

Gohto Y., Obana A., Kanai M., Nagata S., Miki T., Nakajima S. (2000b): Photodynamic therapy for corneal neovascularization using topically administered ATX-S10 (Na). Ophthalmic Sur. Lasers 31, 55-60

Harma M., Harma M., Erel O. (2005): Oxidative stress in women with preeclampsia. Am. J. Obstet. Gynecol. 192, 656-657 http://dx.doi.org/10.1016/j.ajog.2004.07.094

Henderson B. W., Dougherty T. J. (1992): How does photodynamic therapy work? Photochem. Photobiol. 55, 145-157 http://dx.doi.org/10.1111/j.1751-1097.1992.tb04222.x

Hosseini H., Nejabat M. (2007): A potential therapeutic strategy for inhibition of corneal neovascularization with new anti-VEGF agents. Med. Hypotheses 68, 799-801 http://dx.doi.org/10.1016/j.mehy.2006.06.063

Ichikawa K., Takeuchi Y., Yonezawa S., Hikita T., Kurohane K., Namba Y., Oku N. (2004): Antiangiogenic photodynamic therapy (PDT) using Visudyne causes effective suppression of tumor growth. Cancer Lett. 205, 39-48 http://dx.doi.org/10.1016/j.canlet.2003.10.001

Kim S. W., Ha B. J., Kim E. K., Tchah H., Kim T. (2008): the effect of topical bevacizumab on corneal neovascularization. Ophthalmology 115, 33-38 http://dx.doi.org/10.1016/j.ophtha.2008.02.013

Koksal H., Kurban S. (2010): Total oxidant status, total antioxidant status, and paraoxonase and arylesterase activities during laparoscopic cholecystectomy. Clinics 65, 285-290 http://dx.doi.org/10.1590/S1807-59322010000300008 
Koller-Lucae S. K., Schott H., Schwendener R. A. (1999): Low-density lipoprotein and liposome mediated uptake and cytotoxic effect of N4-octadecyl-1- $\beta$-D-arabinofuranosylcytosine in Daudi lymphoma cells. Br. J. Cancer 80, 1542-1549 http://dx.doi.org/10.1038/sj.bjc.6690558

Koracevic D., Koracevic G., Djordjevic V., Andrejevic S., Cosic V. (2001): Method for the measurement of antioxidant activity in human fluids. J. Clin. Pathol. 54, 356-361 http://dx.doi.org/10.1136/jcp.54.5.356

Laemmli U. K. (1970): Cleavage of structural proteins during the assembly of the head of bacterophage T4. Nature 227, 680-685 http://dx.doi.org/10.1038/227680a0

Lee P., Wang C. C., Adamis A. P. (1998): Ocular neovascularization an epidemiologic review. Surv. Ophthalmol. 43, 245-269 http://dx.doi.org/10.1016/S0039-6257(98)00035-6

Lowry O. H., Rosebrough N. J., Farr A. L., Randall R. J. (1951): Protein measurements with the folin phenol reagent. J. Biol. Chem. 193, 265-275

Lukšienè Ž. (2003): Photodynamic therapy: mechanism of action and ways to improve the efficiency of treatment. Medicina 39, $1137-1150$

Lynch S. S., Cheng C. M. (2007): Bevacizumab for neovascular ocular diseases. Ann. Pharmaco. Ther. 41, 614-625 http://dx.doi.org/10.1345/aph.1H316

Marsh R. J. (1988): Argon laser treatment of lipid keratopathy. Br. J. Ophthalmol. 72, 900-904 http://dx.doi.org/10.1136/bjo.72.12.900

Martinez R., Quintana K., Navarro R., Martin C., Hernandes M. L., Aurrekoetxea I., Ruiz-Sanz J. I., Lacort M., Ruiz-Larrea M. B. (2002): Pro-oxidation and antioxidant potential of catecholestrogens against ferryl-myoglobin-induced oxidative stress. Biochem. Biophys. Acta 1583, 167-175 http://dx.doi.org/10.1016/S1388-1981(02)00207-X

Nirankari V. S., Bear J. C. (1986): Corneal argon laser photocoagulation for neovascularization in penetrating keratoplasty. Ophthalmology 93, 1304-1309

Nowak-Sliwinska P., Karocki A., Elas M., Pawlak A., Stochel G., Urbanska K. (2006): Verteporfin, photofrin II, and merocyanine
540 as PDT photosensitizers against melanoma cells. Biochem. Biophys. Res. Commun. 349, 549-555 http://dx.doi.org/10.1016/j.bbrc.2006.08.060

Ohkawa H., Ohishi N., Yagi K. (1979): Assay for lipid peroxides in animal tissues by thiobarbituric acid reaction. Anal. Biochem. 95, 351-358

http://dx.doi.org/10.1016/0003-2697(79)90738-3

Pan G., Oie S., Lu D. R. (2004): Uptake of the carborane derivative of cholesteryl ester by glioma cancer cells is mediated through LDL receptors. Pharm. Res. 21, 1257-1262 http://dx.doi.org/10.1023/B:PHAM.0000033014.04820.a7

Rabus M., Demirbağ R., Sezen Y., Konukoğlu O., Yildiz A., Erel Ö., Zeybek R., Yakut C. (2008): Plasma and tissue oxidative stress index in patients with rheumatic and degenerative heart valve disease. Arch. Turk. Soc. Cardiol. 36, 536-540

Schmidt-Erfurth U., Hasan T., Schomacker K., Flotte T., Birngruber R. (1995): In vivo uptake of liposomal benzoporphyrin derivative and photothrombosis in experimental corneal neovascularization. Laser Surg. Med. 17, 178-188 http://dx.doi.org/10.1002/lsm.1900170207

Snedecore G. W., Cochran W. G. (1976): Statistical Methods. 6th ed., Ames, Iowa University Press, USA

Wayner D. D., Burton G. W., Ingold K. U., Barclay L. R., Locke S. J. (1987): The relative contributions of vitamin $\mathrm{E}$, urate, ascorbate and proteins to the total peroxyl radical-trapping antioxidant activity of human blood plasma. Biochem. Biophys. Acta 924, 408-419 http://dx.doi.org/10.1016/0304-4165(87)90155-3

Yanik M., Erel O., Kati M. (2004): The relationship between potency of oxidative stress and severity of depression. Acta Neuropsychiatr. 16, 200-203 http://dx.doi.org/10.1111/j.0924-2708.2004.00090.x

Yeni E., Gulum M., Selek S., Erel O., Unal D., Verit A., Savas M. (2005): Comparison of oxidative/antioxidative status of penile corpus cavernosum blood and peripheral venous blood. Int. J. Impot. Res. 17, 19-22 http://dx.doi.org/10.1038/sj.ijir.3901262

Received: April 18, 2012

Final version accepted: June 7, 2012 